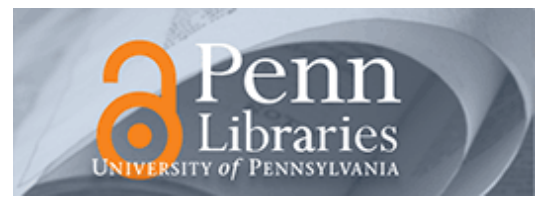

University of Pennsylvania

ScholarlyCommons

Management Papers

Wharton Faculty Research

9-2017

\title{
Perceptions of High Integrity Can Persist after Deception: How Implicit Beliefs Moderate Trust Erosion
}

\author{
Michael P. Haselhuhn \\ Maurice E. Schweitzer \\ University of Pennsylvania \\ Laura J. Kray \\ Jessica A. Kennedy
}

Follow this and additional works at: https://repository.upenn.edu/mgmt_papers

Part of the Cognition and Perception Commons, Cognitive Psychology Commons, Experimental Analysis of Behavior Commons, Interpersonal and Small Group Communication Commons, Management Sciences and Quantitative Methods Commons, and the Personality and Social Contexts Commons

\section{Recommended Citation}

Haselhuhn, M. P., Schweitzer, M. E., Kray, L. J., \& Kennedy, J. A. (2017). Perceptions of High Integrity Can Persist after Deception: How Implicit Beliefs Moderate Trust Erosion. Journal of Business Ethics, 145 (1), 215-225. http://dx.doi.org/10.1007/s10551-017-3649-5

This paper is posted at ScholarlyCommons. https://repository.upenn.edu/mgmt_papers/315

For more information, please contact repository@pobox.upenn.edu. 


\title{
Perceptions of High Integrity Can Persist after Deception: How Implicit Beliefs Moderate Trust Erosion
}

\begin{abstract}
Scholars have assumed that trust is fragile: difficult to build and easily broken. We demonstrate, however, that in some cases trust is surprisingly robust-even when harmful deception is revealed, some individuals maintain high levels of trust in the deceiver. In this paper, we describe how implicit theories moderate the harmful effects of revealed deception on a key component of trust: perceptions of integrity. In a negotiation context, we show that people who hold incremental theories (beliefs that negotiating abilities are malleable) reduce perceptions of their counterpart's integrity after they learn that they were deceived, whereas people who hold entity theories (beliefs that negotiators' characteristics and abilities are fixed) maintain their first impressions after learning that they were deceived. Implicit theories influenced how targets interpreted evidence of deception. Individuals with incremental theories encoded revealed deception as an ethical violation; individuals with entity theories did not. These findings highlight the importance of implicit beliefs in understanding how trust changes over time.
\end{abstract}

\section{Keywords}

negotiation, trust, deception, trust dynamics

\section{Disciplines}

Cognition and Perception | Cognitive Psychology | Experimental Analysis of Behavior | Interpersonal and Small Group Communication | Management Sciences and Quantitative Methods | Personality and Social Contexts 


\title{
Perceptions of High Integrity Can Persist after Deception:
}

How Implicit Beliefs Moderate Trust Erosion

\author{
Michael P. Haselhuhn \\ University of California, Riverside
}

Maurice E. Schweitzer

University of Pennsylvania

Laura J. Kray

University of California, Berkeley

Jessica Kennedy

Vanderbilt University

Corresponding author:

Michael P. Haselhuhn

University of California, Riverside

900 University Ave.

234 Anderson Hall

Riverside, CA 92521

E-mail: michael.haselhuhn@ucr.edu 


\begin{abstract}
Scholars have assumed that trust is fragile: difficult to build and easily broken. We demonstrate, however, that in some cases trust is surprisingly robust — even when harmful deception is revealed, some individuals maintain high levels of trust in the deceiver. In this paper, we describe how implicit theories moderate the harmful effects of revealed deception on a key component of trust: perceptions of integrity. In a negotiation context, we show that people who hold incremental theories (beliefs that negotiating abilities are malleable) reduce perceptions of their counterpart's integrity after they learn that they were deceived, whereas people who hold entity theories (beliefs that negotiators' characteristics and abilities are fixed) maintain their first impressions after learning that they were deceived. Implicit theories influenced how targets interpreted evidence of deception. Individuals with incremental theories encoded revealed deception as an ethical violation; individuals with entity theories did not. These findings highlight the importance of implicit beliefs in understanding how trust changes over time.
\end{abstract}


Trust enables social groups, organizations and economic systems to operate effectively (Dirks \& Ferrin, 2001; Fukuyama, 1996; Lewicki \& Bunker, 1996). At the same time, individuals, groups, and organizations routinely engage in actions that violate trust (Elangovan \& Shapiro, 1998). Despite the importance of trust and the frequency with which trust is violated, we know little about how trust changes over time. In particular, we know very little about how trust is harmed by violations (Kim, Ferrin, Cooper \& Dirks, 2004; Schoorman, Mayer \& Davis, 2007; Schweitzer, Hershey \& Bradlow, 2006).

Prior research has assumed that trust is fragile: slow to build and easy to break. In several theoretical articles, scholars have postulated that trust violations substantially and irreparably harm trust (e.g., Kramer, 1996; Lewicki, 2006; Boyle \& Bonacich, 1970). However, empirical work investigating trust erosion, or whether and how trust is lost following a transgression (Elangovan, Auer-Rizzi, \& Szabo, 2007), remains scarce.

Perceptions of trustworthiness precede trust judgments and are rooted in perceptions of ability, benevolence and integrity (Mayer \& Davis, 1999; Mayer et al., 1995). Different types of actions can independently affirm or violate different dimensions of trust (Kim et al., 2004). In this paper, we focus on violations of integrity (i.e., departures from socially-accepted morals or principles; Kim et al., 2004; Mayer et al., 1995), which are directly linked with deception and trust (Levine \& Schweitzer, 2015). We describe how perceived integrity changes following deception, and adopt the term trust erosion to refer to a decrease in perceived integrity. We challenge prior theoretical work by demonstrating that in some cases, transgressions harm assessments of a counterpart's integrity very little. In particular, we argue that individual differences in implicit theories about the stability of human nature influence the attributions 
people make for the behavior they observe, and these theories moderate the relationship between trust violations and trust erosion.

By exploring the relationships among implicit theories and reactions to being deceived, we extend theory and research in a number of important ways. Whereas previous work on dynamic trust has focused primarily on how trust can be rebuilt following extreme and repeated violations (Bottom, Gibson, Daniels, \& Murnighan, 2002; Schweitzer, Hershey \& Bradlow, 2006; Lount, Zhong, Sivanathan \& Murnighan, 2008), the current research examines the conditions under, and the extent to which, perceived integrity might erode in the first place. We highlight the social-cognitive underpinnings of trust, and demonstrate how the implicit theories of perceivers are a critical factor in determining how they respond to untrustworthy behavior.

\section{Implicit Theories}

Individuals hold implicit theories about the fixedness or malleability of key attributes, such as intelligence and leadership (Dweck, 1996). Some people believe that even the most basic qualities that characterize a person can be changed through effort and hard work (incremental or malleable implicit theories), while others believe that basic qualities cannot change over time (entity or fixed theories; Chiu, Hong \& Dweck, 1997; Dweck et al., 1993; Dweck \& Leggett, 1988). Although implicit theories are rarely articulated and often operate below the level of conscious awareness, they can exert powerful effects on affect, cognition, and behavior (e.g., Heslin, VandeWalle \& Latham, 2006; Hong et al., 1997). For instance, entity theories promote stereotyping by leading individuals to characterize others as immutably situated within a socially-defined category (Levy, Stroessner \& Dweck, 1998), and implicit negotiation theories affect negotiators' ability to create and claim value and to extract valuable lessons from prior negotiations (Kray \& Haselhuhn, 2007; Wong, Haselhuhn \& Kray, 2011). 
Though implicit theories are often studied as stable, trait-like individual characteristics (e.g., Heslin et al., 2006), several studies demonstrate that implicit theories can be manipulated situationally. Simple inductions, such as reading an essay espousing either an incremental or entity view, can influence the implicit theories that people hold (e.g., Bergen, 1992; Chiu et al., 1997; Kray \& Haselhuhn, 2007). The labile nature of implicit theories is particularly relevant in an applied context - actors may wish to shift the implicit theories of others in order to achieve specific goals. For example, managers may wish to induce incremental implicit negotiation theories in their employees in order to make them more effective negotiators (Kray \& Haselhuhn, 2007).

Importantly, implicit theories affect the attributions people make for others' behavior. Entity theorists view people in terms of fixed traits (i.e., people cannot change). Incremental theorists are more likely to believe that situational moderators influence behavior (Dweck, Chiu \& Hong, 1995; Dweck, Hong \& Chiu, 1993). For instance, Hong et al. (1999) found that entity theorists attributed negative outcomes (e.g., poor test performance) to stable traits (e.g., innate ability), whereas incremental theorists attributed these negative outcomes to both stable and changeable factors, such as effort.

Because entity theorists believe that behavior stems from stable, underlying traits, they place a great deal of weight on even limited information about others and believe that this information has substantial predictive power (Dweck et al., 1993). For example, Chiu et al. (1997b) found that, relative to incremental theorists, entity theorists believed that a single observation of a behavior (e.g., being friendly or honest) suggested a high probability that the person would exhibit the same behavior in a completely different situation. 
These findings suggest that initial impressions are very important for entity theorists, as these initial impressions are difficult to change. This is true even when entity theorists receive disconfirming evidence. Whereas incremental theorists attend equally to belief-confirming and belief-disconfirming information, entity theorists tend to focus primarily on information that confirms held beliefs about an individual or group (Plaks et al., 2001). For instance, Gervey et al. (1999) examined how implicit theories affected jury decisions in a fictional court case. Entity theorists based their verdicts primarily on the initial positive or negative surface descriptions of the defendant, largely ignoring whether the evidence supported this judgment. Incremental theorists, on the other hand, based their verdicts on the quality of the total body of evidence, regardless of their initial perceptions.

Similarly, Heslin et al. (2005) found that, in an organizational context, supervisors who held entity theories were slower to update initial perceptions of their subordinates (either positive or negative) in the face of new information suggesting that the subordinate's performance had changed. Plaks, Grant \& Dweck (2005) argued that entity theorists avoid or attempt to debunk belief-inconsistent information not only because they believe it less likely to be true, but also because if it were to be true, it would violate their most basic beliefs that people cannot really change.

In sum, implicit theories have been shown to influence the knowledge people believe they have about others. Entity theorists believe that they can learn a great deal about other people from even single observations. They expect behaviors and attitudes to remain stable over time and across varied contexts, and are resistant to information that suggests that their initial impressions may have been incorrect. Incremental theorists, on the other hand, are more likely to 
attribute observed behaviors to situational forces, and are therefore receptive to information that either confirms or disconfirms their initial perceptions of others.

\section{Implicit Theories and Trust Erosion}

Entity theorists are motivated to see the world as stable and dispositional (Plaks et al., 2005). As a result, entity theorists are quick to reach conclusions about people's basic characteristics (e.g., trustworthiness) and slow to update these perceptions when they learn new information (Heslin et al., 2005). When exposed to belief-inconsistent information, entity theorists engage in biased processing by undervaluing information that contradicts their beliefs. As a result, we expect first impressions of integrity to be particularly enduring for entity theorists. For example, if an entity theorists believes someone to have high integrity, we expect them to discount the importance of a trust violation and other belief-inconsistent information (cf. Robinson, 1996). That is, we expect entity theorists to engage in biased and motivated information processing (e.g., Kunda, 1990) to preserve their initial impressions of a counterpart.

Conversely, we expect incremental theorists to be more likely to revise their beliefs. Compared to entity theorists, incremental theorists are more attentive to both belief-consistent and belief-inconsistent information and, as a result, are more likely to incorporate trust violations in their assessments and update their perceptions of a counterparts' integrity. In sum, we expect incremental theorists' perceptions of a counterpart, in contrast to an entity theorists' perceptions, to decline more quickly following a trust violation. As a result, we expect incrementalists to be more accurate in processing belief-inconsistent information than entity theorists.

Taken together, implicit theories are likely to influence trust erosion in two ways. First, entity theorists are less likely to recognize objective violations of trust. Second, even when 
controlling for differences in perceptions of trust violations, entity theorists experience less trust erosion than will incremental theorists. Formally, we hypothesize:

H1: Entity theorists will experience less trust erosion following deception than will incremental theorists.

$\mathrm{H} 2$ : Entity theorists will ignore or discount information that is inconsistent with their initial beliefs regarding perceptions of a counterpart's integrity.

H3: Biased processing of belief-inconsistent information will mediate the relationship between implicit theories and trust erosion.

In our studies, we describe how deception affects perceived integrity within the domain of negotiations. Although trust benefits negotiators by enabling participants to share information and reach efficient, integrative outcomes (Bazerman, 2006; Butler, 1999; Kimmel et al., 1980; Lewicki, 2006; Maddux, Mullen \& Galinsky, 2008; Thompson, 1991), negotiators routinely engage in deception to gain leverage and claim additional surplus (Kray \& Haselhuhn, 2012; Lax \& Sebenius, 1986; O’Connor \& Carnevale, 1997; Schweitzer, 2001; Schweitzer \& Croson, 1999). Because negotiator reputations are only loosely tied to their history of behavior (Anderson $\&$ Shirako, 2008), negotiations are a perfect context for examining whether implicit theories influence the degree to which perceived integrity is informed by actual behavior. We measure negotiators' perceptions of their counterpart both before and after being deceived, and describe the effects of deception on perceived integrity and demonstrate that implicit theories moderate this relationship. 
We examine the relationship between deception and integrity perceptions in a negotiation context. Domain-specific implicit beliefs can substantially influence both judgment and behavior (Hong et al., 1997; Kray \& Haselhuhn, 2007; Tamir et al., 2007), and in this study we focus on implicit negotiation theories (Kray \& Haselhuhn, 2007; Kray \& Haselhuhn, 2012). Implicit negotiation theories characterize the view that people either can or cannot change their most basic negotiation characteristics, such as how they approach conflict situations.

In this study, we consider the role of implicit negotiation theories in moderating reactions to revealed deception. We expect people who hold entity theories, beliefs that negotiation characteristics are fixed, to fail to integrate new information. Specifically, compared to people who have incremental theories, we expect people who hold entity theories to maintain initial perceptions of their counterpart's high integrity even after they learn that their counterpart engaged in deception.

\section{Method}

\section{Participants}

Ninety-four MBA students at an East Coast university participated in a negotiation as part of a class exercise. We randomly assigned participants to either a buyer or seller role and to one of two implicit negotiation theory inductions: incremental theories (malleable beliefs) or entity theories (fixed beliefs) in a fully crossed design. Buyers and sellers were randomly assigned to negotiating dyads $(n=47)$, with the qualification that partners had not previously negotiated with one another. ${ }^{1}$

\section{Materials and Procedure}

The negotiation involved five stages. First, one week before the experiment, participants were given negotiation materials regarding the potential sale of a property to prepare in advance. 
The negotiation exercise, detailed below, creates the opportunity and incentive for buyers to mislead their counterpart. After preparing for the negotiation, participants completed the remainder of the experiment via computer.

Second, we manipulated negotiator implicit theories (described below). Third, we gave participants 80 minutes to negotiate. Fourth, after negotiating participants completed a postnegotiation survey to assess their perceptions of their counterpart's integrity and whether they thought they had been deceived. Following this survey, we informed sellers about the buyers' real intentions. In almost every case, this information revealed to sellers that their buyer counterpart had deceived them. Fifth, participants completed a final survey to assess perceptions of their counterpart and whether they thought they had been deceived. We tested our hypotheses by examining how sellers' perceptions of their counterparts' integrity changed after learning of their counterparts' deception.

Implicit negotiation theory manipulation. Though we were primarily interested in seller reactions to deception, we randomly and independently assigned both buyers and sellers to the entity or the incremental negotiation theory condition. ${ }^{2}$

We manipulated implicit theories with the Kray and Haselhuhn (2007) induction. We chose to manipulate, rather than measure, implicit theories in order to establish the causal relationship between implicit theories and trust erosion. Prior to negotiating, participants read either the entity or the incremental version of an induction essay. We informed participants that reading this essay would help "put them in a negotiation frame of mind." The incremental theory version of the essay included reports from fictitious studies supporting the position that people can change who they are as negotiators. Sample statements from the essay include "no one's negotiation character is hard like a rock that cannot be changed," and "a voluminous body of 
evidence indicates that the manner in which people approach conflict situations is changeable." The entity theory version of the essay endorsed the position that negotiators' characteristics are relatively fixed. Sample statements include "people gain experience and develop in negotiations, but they do so on the foundation of enduring dispositions," and "a voluminous body of evidence indicates that the manner in which people approach conflict situations is not changeable."

Negotiation exercise. We modified the Bullard Houses negotiation case (Karp, Gold \& Tan, 2006) to make the issue of deception unambiguous. This exercise involves a seller interested in selling a property to a buyer only if the buyer can guarantee that the property will be preserved, and a buyer who is unwilling to make any guarantees. This exercise is characterized by a positive bargaining zone in terms of financial concerns, but a negative bargaining zone in terms of each party's underlying interests. Agreement is very difficult to reach, and only 14 of the 47 dyads reached an agreement within the allotted time. In our modified version of this exercise, it was very clear to sellers that they would only be willing to sell the property if it would be preserved and not developed for commercial use. It was equally clear to buyers that they were only interested in developing the property for commercial use. We informed buyers that they were not allowed to reveal their intentions for the property (the planned construction of a hotel).

Two research assistants who were blind to hypotheses and conditions coded buyer deception from the transcripts of the negotiation; inter-rater agreement was adequate $(\kappa=.56)$. In 44 of the 47 transcripts (94\%), at least one rater noted that the buyer had engaged in deception. The pattern and significance of the results remain unchanged when including or excluding participants who experienced no deception. The analyses presented below were conducted with data excluding those who did not experience deception. 
Perceived deception. Consistent with prior deception research (Barry, 1999; Lewicki, 1983), we asked sellers to rate the extent to which their counterpart had misrepresented their bottom line, preferences, emotions, intentions, and material facts (1: Definitely misrepresented, 5: Definitely did not misrepresent). We asked sellers to complete this scale both immediately following the negotiation $(\alpha=.94)$ and after we revealed buyers' true intentions $(\alpha=.94)$. In subsequent analyses, we report results from the average of the five items, and we reverse-scored responses so that higher numbers indicate greater perceived deception.

Perceived integrity. We measured the integrity component of trust (Mayer et al., 1995) using a three item scale adapted from Kim et al. (2004). We collected this measure both immediately following the negotiation $(\alpha=.93)$ and after we revealed the buyers' true intentions $(\alpha=.95)$. Specifically, participants indicated the extent to which they agreed with the following three statements: I like my counterpart's values; Sound principles seem to guide my counterpart's behavior; My counterpart has a great deal of integrity (1: Strongly disagree, 7: Strongly agree).

Pilot study

We conducted a pilot study with a separate population to test whether our induction would hold after 80 minutes of intense negotiation. ${ }^{3}$ We recruited 68 undergraduate students to participate for extra course credit. Participants were randomly assigned to read the incremental theory manipulation essay $(n=30)$ or the entity theory manipulation essay $(n=38)$. Two days later, participants completed a 7-item scale that measures beliefs about the malleability of negotiator characteristics (Kray \& Haselhuhn, 2007). Sample items include "good negotiators are born that way" and "all people can change even their most basic negotiator characteristics" (1: 
Very strongly disagree, 7: Very strongly agree). Higher scores indicate greater incremental theories $(\alpha=.76)$.

Results of a one-way ANOVA showed that participants in the incremental theory condition $(M=5.41, S D=.59)$ held significantly more malleable theories compared to those in the entity theory condition $(M=4.44, S D=.87), F(1,66)=27.50, p<.001$. These results suggest that the simple induction employed in our research holds after a significant period of time.

Results and Discussion

Initial integrity perceptions. Deception is generally difficult to detect (Ekman \& O'Sullivan, 1991). Consistent with this previous work, sellers' perceptions of integrity immediately following the negotiation did not correlate with buyers' deception $(r(44)=-.11, \mathrm{~ns})$; even though all buyers engaged in deception, sellers initially reported moderate levels of perceived integrity in their counterpart, $(M=4.20, S D=0.18)$. In a regression modeling seller initial integrity perceptions as a function of seller theories and buyer theories, we found no significant main or interaction effects.

Perceived deception. We predicted that implicit theories would moderate reactions to potentially untrustworthy actions, such that entity theorists would be less likely to perceive a trusted counterpart's actions as deceptive. To test this prediction, we conducted a mixed-model ANOVA with perceived deception as the dependent measure, implicit theories as a betweensubjects factor, and time (before or after the deception was revealed) as a within-subject factor.

We first observed a significant main effect of time, such that buyers were perceived as less deceptive immediately following the negotiation $(M=2.69, S D=0.89)$ than they were after we revealed the buyer's true intentions $(M=3.28, S D=1.22), F(1,42)=14.13, p=.001$. This 
main effect was qualified by a significant interaction between implicit theories and time, $F(1,42)$ $=7.16, p=.01$. After we revealed the buyers' true intentions, participants in the incremental theory condition were significantly more likely to perceive that they had been deceived by their counterpart $(M \mathrm{~s}=2.52$ vs. $3.61, S D \mathrm{~s}=1.10$ and 1.19$), F(1,19)=15.83, p=.001$; perceived deception did not significantly differ across time for participants in the entity theory condition $(M s=2.83$ vs. $3.01, S D s=0.65$ and 1.21$), F(1,23)=.77$, ns (see Figure 1$).$ Entity theorists and incremental theorists did not significantly differ in either their initial perceptions $(F(1,42)=$ $1.30, p=.26)$, nor their perceptions following the revealed deception, $F(1,42)=2.75, p=.11$. These results supported Hypothesis 2.

Perceived integrity. We hypothesized that entity theorists' failure to recognize deceptive behavior would lead them to experience less trust erosion compared to incremental theorists. To test this prediction, we conducted a mixed-model ANOVA with implicit theories as a betweensubjects factor and time (before or after the deception was revealed) as a within-subject factor.

This analysis first revealed a significant main effect of time, such that perceptions of integrity were significantly higher immediately after the negotiation $(M=4.20, S D=1.18)$ compared to after the buyers' true intentions were revealed $(M=3.42, S D=1.36), F(1,42)=$ $19.84, p<.001$. However, consistent with our hypothesis, this main effect was qualified by a significant interaction between implicit theories and time (see Figure 2), $F(1,42)=11.78, p=$ .001. Participants in the incremental theory condition perceived significantly less integrity after the buyers' true intentions were revealed $(M \mathrm{~s}=4.47$ vs. $2.97, S D \mathrm{~s}=1.33$ and 1.31$), F(1,19)=$ $18.81, p<.001$. In contrast, participants in the entity theory condition did not change their perceptions after the information was revealed, $(M \mathrm{~s}=3.99$ vs. $3.79, S D \mathrm{~s}=1.02$ and 1.31$), F(1$, $23)=1.00$, ns. Similarly, whereas our preliminary analyses showed no differences in initial 
perceptions of integrity between entity and incremental theorists $(F(1,42)=1.84, p=.18)$, after we revealed the buyers' true intentions, participants in the incremental condition perceived significantly less integrity in their counterparts than did participants in the entity condition, $F(1$, $42)=4.34, p=.04$. This analysis supported Hypothesis 1 .

We next tested the mediating role of perceived deception on trust erosion after the buyers' deception was revealed. We included measures of perceived integrity and perceived deception immediately following the negotiation as controls in all analyses. To test for mediation, we conducted bias-corrected bootstrapping analyses with 10,000 resamples (Preacher $\&$ Hayes, 2008). This analysis revealed a significant indirect effect of the implicit theory induction, Mediated effect $=-.58, S E=.26,95 \% C I=-1.19--.16$. As the confidence interval does not bridge zero, this analysis supports our conclusion that perceived deception mediated the relationship between implicit theories and trust erosion, consistent with Hypothesis 3.

We also conducted supplemental analyses to explore the relationship between implicit theories and trust erosion. Specifically, we examined whether entity theorists' higher perceived integrity after a trust violation results from their lower perceived deception. To do so, we constructed difference scores for the perceived integrity and perceived deception measures by subtracting the respective scores at Time 1 from scores at Time 2 . We then tested whether the perceived deception score mediated the relationship between implicit theories and the perceived integrity score. Consistent with our previous results, we found a significant indirect effect of implicit theories, Mediated effect $=-.53, S E=.25,95 \% C I=-1.16--.15$.

These findings support Hypotheses 1, 2, and 3. Individuals' theories regarding the fixedness of negotiator characteristics moderated responses to deception. In particular, by inducing entity theories, individuals maintained perceptions of integrity in a negotiation 
counterpart even after learning of the counterpart's deceitful behavior. In contrast, by inducing incremental theories, individuals reduced perceptions of integrity in their counterparts after learning that their counterpart had been deceitful. By manipulating, rather than measuring, implicit negotiation theories, we were able to establish a causal relationship between implicit theories and trust erosion.

Intriguingly, perceived deception mediated the relationship between implicit theories and trust erosion. Whereas individuals in the incremental theory condition recognized that they had been deceived when they learned their counterparts' true intentions, individuals in the entity theory condition did not update their beliefs about the other party in the face of the new information. Even though sellers in both conditions were deceived, those with entity theories may have ignored or discounted the belief-inconsistent information.

Taken together, our findings link implicit theories, deception, and trust erosion. However, our study did not address how individuals process belief-inconsistent information. When confronted with new information, individuals motivated to maintain their current beliefs may either disregard the new information or discount the importance of the new information. For example, in our study, entity theorists could either ignore new information about buyers' intentions or they might encode their counterpart's misrepresentations as part of a negotiation process, and hence not a serious violation, rather than judge their counterpart to have committed an ethical violation. Kray and Haselhuhn (2012) found negotiators holding entity theories report lower ethical standards than incremental theorists, suggesting the former may be less likely than the latter to judge the identical behavior as unethical. To disentangle these potential explanations, we conducted a second study to explore how entity theorists process and integrate new information that conflicts with previously held beliefs. 
We extend our investigation in Study 2 in two other respects as well. First, Study 2 examined the relation between implicit theories and trust using a larger sample. Second, we address the potential concern that the implicit theory induction we used in Study 1 may fade over time. Though similar implicit theory inductions have resulted in long-lasting effects in other studies (see Haselhuhn, Schweitzer \& Wood, 2010; Kray \& Haselhuhn, 2007), and our pilot results suggest that our manipulation is durable, we address concerns regarding the robustness of the implicit theory-trust erosion relationship in Study 2. Specifically, we establish convergent validity by measuring naturally-occurring individual differences in implicit theories, rather than inducing particular beliefs.

Study 2

In Study 2, we extend our investigation by examining whether incremental theorists and entity theorists differentially attend to untrustworthy behavior (Hypothesis 2). Specifically, we examine whether implicit theories predict the degree to which behavior affects ethical attributions for a counterpart's actions, and subsequently informs perceived integrity. In addition, in contrast to Study 1, this study measures rather than manipulates implicit theories. This approach enables us to determine whether naturally-occurring individual differences in implicit theories influence trust erosion.

Method

\section{Participants}

We recruited 258 U.S. participants through Amazon Mechanical Turk, and we paid individuals $\$ .75$ for their participation. 


\section{Materials and Procedure}

First, we measured participants' implicit negotiation theories. Then, we asked participants to read a scenario about purchasing a used computer. After learning about the computer, participants read the following information:

You arrange a meeting with the seller and see that the computer is very clean and has been well maintained. You ask the seller if he has had any issues with the computer, and he assures you that the computer is in perfect working order. You decide to purchase the computer.

Following the initial scenario, participants rated the seller's perceived integrity (see details below).

After recording their initial impressions, participants received updated information that suggests that the seller engaged in deception. Specifically, participants were told:

After using the computer for a few weeks, you find that the hard drive acts like it is about to fail, and the computer occasionally crashes without warning. When you take the computer to a local repair shop, the salesperson pulls up a repair record for the computer and notes that it was brought to the shop just last month with similar issues.

After reading the new information, participants once again rated the seller's perceived integrity and also stated their beliefs regarding the seller's motives in the interaction.

Implicit negotiation theories. Before providing participants with the scenario, we administered Kray and Haselhuhn's (2007) implicit negotiation theory scale $(\alpha=.86)$.

Perceived integrity. We once again measured the integrity component of trust (Mayer et al., 1995) using the 3-item scale adapted from Kim et al. (2004). Reliability was adequate for 
both initial perceptions of integrity $(\alpha=.88)$ and perceptions of integrity after the updated information was revealed $(\alpha=.93)$.

Ethical attributions for seller behavior. We asked participants to assess the seller's motives by responding to the following open-ended question, "In your own words, how would you explain the Seller's approach to the transaction?" Two research assistants who were blind to the study hypotheses coded responses based upon whether or not the participant specifically described the seller's behavior using words related to ethics or morality (e.g., lying, cheating, immoral, deceitful). Examples of motives including such rationale (coded as 1) included: "It was dishonest and ethically wrong," and "He was lying and didn't care what he had to do to get rid of a computer." Examples of responses that did not include specific reference to ethical or moral considerations (coded as 0 ) included: "He was a guy who wanted to get rid of a computer. He probably thought the issue was fixed but still wanted to get rid of it just in case," and "The seller approached the transaction well making me feel secure enough to buy." Inter-rater reliability was adequate $(\kappa=.69)$ and disagreements were resolved by a third research assistant.

\section{Results}

Preliminary analyses. Our predictions are predicated on the assumption that individuals will initially trust their counterparts following the transaction. Indeed, participants reported a moderately high level of perceived integrity following the first part of the scenario $(M=5.15, S D$ $=0.88$ on a 7 -point scale).

Trust erosion. Correlations between all variables are presented in Table 1. We conducted a repeated-measures ANOVA to investigate perceived integrity before and after ethicallyquestionable information about the transaction was revealed. To test the role of implicit negotiation theories in this process, we included implicit theories as a continuous predictor. This 
analysis first revealed a significant main effect of time. Perceived integrity was significantly greater immediately following the transaction $(M=5.15, S D=0.88)$ compared to after the seller's deceptive behavior was revealed $(M=1.74, S D=0.98), F(1,256)=30.99, p<.001$. This main effect for time was qualified by a significant interaction with implicit theories, $F(1,256)=$ $8.07, p=.005$. To explore this interaction, we correlated implicit theories with perceptions of integrity before and after the history of the computer was revealed. We found no significant relationship between implicit theories and initial perceptions of integrity, $r(258)=.10, p=.12$. However, we find a significant negative relationship between implicit theories and perceptions of integrity after we revealed the new information $(r(258)=-.14, p=.02)$; individuals with entity theories perceived more integrity in their counterpart following deception than did individuals with incremental theories.

Ethical attributions for seller behavior. Most (74\%) participants explained the seller's behavior in ethical terms compared to more benign interpretations of behavior, $\chi^{2}(1, N=258)=$ $57.69, p<.001$. We tested the relationship between implicit beliefs and attributions about the seller's behavior using logistic regression. Individuals with stronger entity theories were less likely to explain the seller's actions in terms of ethics or morality than were individuals with incremental theories, $b=.30, S E=.15$, Wald $\chi^{2}(1, N=258)=4.34, p=.037$.

We next tested the potential mediating role of ethical attributions on trust erosion using bias-corrected bootstrapping analyses with 10,000 resamples (Preacher \& Hayes, 2008). Specifically, we examined whether ethical attributions mediated the relationship between implicit negotiation theories and perceptions of integrity after the seller's actions were revealed (controlling for levels of initial perceptions following the transaction). This analysis revealed a significant indirect effect of implicit theories, Mediated effect $=-.04, S E=.02,95 \% C I=-.10--$ 
.004. As the confidence interval does not bridge zero, this analysis supports our conclusion that ethical attributions mediated the relationship between implicit theories and trust erosion. As a supplemental analysis, we once again constructed a difference score by subtracting perceived integrity at Time 1 from perceived integrity at Time 2, and determining whether ethical attributions mediated the relationship between implicit theories and this variable. Consistent with our other mediation results, we found a significant indirect effect of implicit theories, Mediated effect $=-.05, S E=.02,95 \% C I=-.11--.02$.

\section{General Discussion}

In this paper, we demonstrate that implicit negotiation theories moderate trust erosion. In Study 1 we induced entity (fixed) or incremental (malleable) theories and in Study 2 we measured these theories. We then assessed the extent to which these theories influenced perceived integrity over time. Even though participants who held both entity and incremental theories were deceived to similar degrees, participants with incremental theories perceived significantly less integrity in their counterparts following the revelation that their counterpart had deceived them. In contrast, people with entity theories maintained their positive perceptions, even after learning of their counterpart's deception. Ethical attributions mediated the relationship between implicit theories and trust erosion. People who held entity theories failed to see a counterpart's deceptive behavior as revealing their integrity; people who held incremental theories were more likely to view their counterpart as deceitful after learning new information.

Our findings demonstrate that the relationship between deception and trust erosion is more complicated than theoretical models of trust erosion have assumed. Not only is it possible for deception to cause surprisingly little harm to trust, but individual differences in general, and implicit theories in particular, also substantially influence trust erosion. 
Our findings regarding the complexity of the relationship between deception and perceptions of integrity are consistent with some prior work. For example, Elangovan et al. (2007) found that perceived intentions matter. When victims attribute violations to intentional behavior, trust is harmed significantly more than when the same behavior is attributed to the inability of the violator to fulfill expectations. In related work, Robinson (1996) found that initial levels of trust moderate the harmful effects of a violation.

Although our current work focuses on how initially high levels of perceived integrity may change over time, our findings could extend to cases in which initial trust is low (e.g., at the beginning of a relationship or after trust has been blatantly violated). Haselhuhn et al. (2010) found that people who hold entity theories (and assume that people cannot readily change) are not very responsive to transgressor's attempts to repair trust (e.g., apologies, explanations of previous behavior, promises that behavior will change in the future). In contrast, people who hold incremental theories are relatively receptive to a transgressor's attempts to rebuild trust.

Our research also has practical implications for individuals and organizations. In practice, people are likely to violate trust both intentionally and unintentionally, and our findings suggest that violators may not suffer distrust after deceiving entity theorists. To avoid exploitation, individuals may need to manage others' impressions of their implicit theories as transgressors may be best able to maintain relationships with others by inducing entity theories in their counterpart before committing (or revealing) untrustworthy actions. Similarly, transgressors may regain trust most effectively by inducing incremental theories in their counterpart prior to taking a trust recovery action (e.g., making an apology). Thus, individuals should be aware of how their own implicit theories shape their perceptions of and reactions to others. 
Our research also complements previous work highlighting the benefits of encouraging incremental theories in organizational and business settings. For example, managers with incremental theories are more likely than those with entity theories to reward improvement in subordinates' performance (Heslin et al., 2005) and to work with subordinates to overcome performance issues in the workplace (Heslin et al., 2006). Similarly, incremental theories lead negotiators to persevere in the face of challenges (Kray \& Haselhuhn, 2007), to overcome negative stereotypes that impede success in strategic interactions (Kray, Locke \& Haselhuhn, 2009), and to avoid the use of unethical actions at the bargaining table (Kray \& Haselhuhn, 2012). Our work does not challenge the benefits of fomenting incremental theories within organizations, but rather builds understanding of the full implications of incremental theories. Trust is a critical element of efficient organizational behavior (Dirks \& Ferrin, 2001; Fukuyama, 1996) and incremental theories may lead to greater fluctuations of trust among organizational members. Our work suggests that leaders who encourage incremental theories within organizations should also consider instituting measures specifically dedicated to maintaining high levels of trust in the workplace.

We have situated our work in literature that suggests entity theorists fixate on early impressions of others. Future work could explore other potential mechanisms by which implicit theories relate to trust dynamics. For example, stronger endorsement of entity theories is associated with greater acceptance of ethically-questionable negotiation tactics, including deception (Kray \& Haselhuhn, 2012). It is possible that because entity theorists see deception as more acceptable, they view deceptive behavior as less reflective of a counterpart's integrity. Future research should further examine the potential links among implicit theories, ethics and trust. 
Future research should also study boundary conditions of the effects we identify in this work. For instance, future work should explore how implicit beliefs relate to trust erosion after repeated violations. We examined a single instance of untrustworthy behavior and found that entity theorists maintained beliefs consistent with their initial perceptions of integrity. Following repeated violations, however, entity theorists may revise their initial perceptions to perceive a counterpart as a particularly untrustworthy individual. Ultimately, these revised perceptions may be resilient in the face of subsequent apologies and future trustworthy behavior.

\section{Conclusion}

Although prior work has assumed that trust is fragile and easily shattered, our work demonstrates that, at least in some cases, trust is remarkably robust. We demonstrate that implicit negotiation theories influence how people react to revealed deception. People who hold incremental theories about negotiators reduce perceived integrity in their counterpart after being deceived more readily than people who hold entity theories about negotiators. In contrast, people who hold entity theories are relatively unlikely to acknowledge that a trust violation has occurred. Our results offer important insight into the social-cognitive basis of trust, and call for increased research into the links between implicit theories and trust. How trust erodes may have more to do with the implicit theories of the target than the transgression itself. 


\section{Footnotes}

${ }^{1}$ We note that though participants had never negotiated with one another prior to this exercise, it is possible that initial impressions may have developed from previous interactions.

${ }^{2}$ Buyers' theories were not significantly related to any of the dependent measures and we focus on sellers' theories in the remaining analyses and discussion.

${ }^{3}$ We thank an anonymous reviewer for noting the importance of establishing the durability of the implicit theory manipulation over time. 


\section{References}

Anderson, C. \& Shirako, A. (2008). Are individuals' reputations related to their history of behavior? Journal of Personality and Social Psychology, 94, 320-333.

Baron, R. M., \& Kenny, D. A. (1986). The moderator-mediator variable distinction in social psychological research: Conceptual, strategic and statistical considerations. Journal of Personality and Social Psychology, 51, 1173-1182.

Barry, B. (1999). The tactical use of emotion in negotiation. In R. Bies, R. Lewicki and B. Sheppard (Eds.), Research on negotiation in organizations (Vol. 7). Greenwich, CT: JAI Press.

Bazerman, M.H. (2006). Judgment in Managerial Decision Making. New York: Wiley.

Bergen, R. (1992). Beliefs about intelligence and achievement-related behaviors. Unpublished doctoral dissertation, University of Illinois at Urbana-Champaign.

Bottom, W. P., Gibson, K., Daniels, S. E., \& Murnighan, J. K. (2002). When talk is not cheap: Substantive penance and expressions of intent in rebuilding cooperation. Organization Science, 13(5), 497-513.

Boyle, R. \& Bonacich, P. (1970). The development of trust and mistrust in mixed-motive games. Sociometry, 33, 123-139.

Butler, J. K. (1999). Trust expectations, information sharing, climate of trust and negotiation effectiveness and efficiency. Group \& Organization Management, 24, 217-238.

Chiu, C., Hong, Y., \& Dweck, C. S. (1997). Lay dispositionism and implicit theories of personality. Journal of Personality and Social Psychology, 73, 19-30.

Dirks, K. \& Ferrin, D. (2001) The role of trust in organizational settings. Organization Science, $12,450-467$. 
Dweck, C.S. (1996). Implicit theories as organizers of goals and behavior. In P.M. Gollwitzer \& J.A. Bargh (Eds.), The Psychology of Action: Linking Cognition and Motivation to Behavior, New York, NY: The Guilford Press.

Dweck, C.S., Chiu, C. \& Hong, Y. (1995). Implicit theories and their role in judgments and reactions: A world from two perspectives. Psychological Inquiry, 6, 267-285.

Dweck, C.S., Hong, Y. \& Chiu, C. (1993). Implicit theories: Individual differences in the likelihood and meaning of dispositional inference. Personality and Social Psychology Bulletin, 19, 644-656.

Dweck, C.S., \& Leggett, E.L. (1988). A social-cognitive approach to motivation and personality. Psychological Review, 95, 256-273.

Ekman, P. \& O’Sullivan, M. (1991). Who can catch a liar? American Psychologist, 46, 913-920.

Elangovan, A.R., Auer-Rizzi, W. \& Szabo, E. (2007). Why don’t I trust you now? An attributional approach to erosion of trust. Journal of Managerial Psychology, 22, 4-24.

Elangovan, A.R. \& Shapiro, D.L. (1998). Betrayal of Trust in Organizations. The Academy of Management Review, 23, 547-566.

Fukuyama, F. (1996). Trust: The Social Virtues and the Creation of Prosperity. New York, NY:Simon and Schuster.

Gervey, B.M., Chiu, C., Hong, Y. \& Dweck, C.S. (1999). Differential use of person information in decisions about guilt versus innocence: The role of implicit theories. Personality and Social Psychology Bulletin, 25, 17-27.

Haselhuhn, M.P., Schweitzer, M.E. \& Wood, A. (2010). How implicit beliefs influence trust recovery. Psychological Science, 21, 645-648.

Heslin, P.A., Latham, G.P. \& VandeWalle, D. (2005). The effect of implicit person theory on 
performance appraisals. Journal of Applied Psychology, 90, 842-856.

Heslin, P.A., VandeWalle, D. \& Latham, G.P. (2006). Keen to help? Managers' implicit person theories and their subsequent employee coaching. Personnel Psychology, 59, 871-902.

Hong, Y., Chiu, C., Dweck, C.S. \& Sacks, R. (1997). Implicit theories and evaluative processes in person cognition. Journal of Personality and Social Psychology, 33, 296-323.

Jap, S.D., Robertson, D.C. \& Hamilton, R. (2011). The dark side of rapport: Agent misbehavior face-to-face and online. Management Science, 57, 1610-1622.

Karp, R., Gold, D. \& Tan, M. (2006). Bullard Houses [Dispute resolution exercise], Cambridge, MA: Harvard University, Harvard Law School, Program on Negotiation.

Kim, P.H., Ferrin, D.L., Cooper, C.D. \& Dirks, K.T. (2004). Removing the shadow of suspicion: The effects of apology versus denial for repairing competence- versus integrity-based trust violations. Journal of Applied Psychology, 89: 104-118.

Kimmel, M.J., Pruitt, D.G., Magenau, J.M., Konar-Goldband, E. \& Carnevale, P.J. (1980). Effects of trust, aspiration, and gender on negotiation tactics. Journal of Personality and Social Psychology, 38, 9-22.

Kramer, R.M. (1996). Divergent realities and convergent disappointments in the hierarchic relation: Trust and the intuitive auditor at work. In R.M. Kramer and T.R. Tyler (Eds.), Trust in organizations: Frontiers of theory and research. Thousand Oaks, CA: Sage.

Kray, L.J. \& Haselhuhn, M.P. (2007). Implicit negotiation beliefs and performance: Longitudinal and experimental evidence. Journal of Personality and Social Psychology, 93, 49-64.

Kray, L.J. \& Haselhuhn, M.P. (2012). Male pragmatism in negotiators' ethical reasoning. Journal of Experimental Social Psychology, 48, 1124-1131. 
Kray, L.J., Locke, C.C., \& Haselhuhn, M.P. (2009). In the words of Larry Summers: Gender stereotypes and implicit beliefs in negotiations. In A. A. Stanton, M. Day, \& I. Welpe (Eds.), Neuroeconomics and the Firm.

Kunda, Z. (1990). The case for motivated reasoning. Psychological Bulletin, 108, 480-498.

Lount, R. B., Zhong, C. B., Sivanathan, N., \& Murnighan, J. K. (2008). Getting off on the wrong foot: The timing of a breach and the restoration of trust. Personality and Social Psychology Bulletin, 34(12), 1601-1612.

Lax, D., \& Sebenius, J. (1986). The Manager as Negotiator: Bargaining for Cooperation and Competitive Gain. New York, NY: Free Press.

Levine, E. E., \& Schweitzer, M. E. (2015). Prosocial lies: When deception breeds trust. Organizational Behavior and Human Decision Processes, 126, 88-106.

Levy, S. R., Stroessner, S. J., \& Dweck, C. S. (1998). Stereotype formation and endorsement: The role of implicit theories. Journal of Personality and Social Psychology, 74, 14211436.

Lewicki, R.J. (2006). Trust, trust development and trust repair. In M. Deutsch, P.T. Coleman \& E.C. Marcus (Eds.), The handbook of conflict resolution: Theory and practice. San Francisco, CA: Jossey-Bass.

Lewicki, R.J. (1983). Lying and deception: A behavioral model. In M.H. Bazerman and R.J. Lewicki (Eds.), Negotiating in organizations. Beverly Hills, CA: Sage.

Lewicki, R. J. \& Bunker, B.B. (1996). Developing and maintaining trust in work relationships. In R.M. Kramer and T.R. Tyler (Eds.), Trust in organizations: Frontiers of theory and research. Thousand Oaks, CA: Sage.

Maddux, W. W., Mullen, E. \& Galinsky, A. D. (2008). Chameleons bake bigger pies and take 
bigger pieces: Strategic behavioral mimicry facilitates negotiation outcomes. Journal of Experimental Social Psychology, 40, 461-468.

Mayer, R.C. \& Davis, J.H. (1999). The effect of the performance appraisal system on trust for management: A field quasi-experiment. Journal of Applied Psychology, 84, 123-136.

Mayer, R.C., Davis, J.H. \& Schoorman, F.D. (1995). An integrative model of organizational trust. Academy of Management Review, 20, 709-734.

O’Connor, K.M. \& Carnevale, P.J. (1997). A nasty but effective negotiation strategy: Misrepresentation of a common-value issue. Personality and Social Psychology Bulletin, 23, 504-515.

Plaks, J.E., Grant, H. \& Dweck, C.S. (2005). Violations of implicit theories and the sense of prediction and control: Implications for motivated person perception. Journal of Personality and Social Psychology, 88, 245-262.

Plaks, J.E., Stroessner, S.J., Dweck, C.S. \& Sherman, J.W. (2001). Person theories and attention allocation: Preferences for stereotypic versus counterstereotypic information. Journal of Personality and Social Psychology, 80, 876-893.

Robinson, S.L. (1996). Trust and the breach of the psychological contract. Administrative Science Quarterly, 41, 574-599.

Robinson, R. J., Lewicki, R. J., \& Donahue, E. M. (2000). Extending and testing a five factor model of ethical and unethical bargaining tactics: Introducing the SINS scale. Journal of Organizational Behavior, 21, 649-664.

Schoorman, F.D., Mayer, R.C. \& Davis, J.H. (2007). An integrative model of organizational trust: Past, present, and future. Academy of Management Review, 32, 344-354.

Schweitzer, M. (2001). Deception in negotiations. In S. Hoch \& H. Kunreuther (Eds.), 
Wharton on Making Decisions. 187-200. New York, NY: Wiley.

Schweitzer, M.E., Brodt, S., \& Croson, R.T. (2002). Seeing and believing: Visual access and the strategic use of deception. The International Journal of Conflict Management, 13, 258275.

Schweitzer, M.E. \& Croson, R.T. (1999). Curtailing deception: The impact of direct questions on lies and omissions. The International Journal of Conflict Management, 10, 225-248.

Schweitzer, M.E., DeChurch, L.A. \& Gibson, D.E. (2005). Conflict frames and the use of deception: Are competitive negotiators less ethical? Journal of Applied Social Psychology, 35, 2123-2149.

Schweitzer, M.E., Hershey, J., \& Bradlow, E. (2006). Promises and lies: Restoring violated trust. Organizational Behavior and Human Decision Processes, 101, 1-19.

Tamir, M., John, O.P., Srivastava, S. \& Gross, J.J. (2007). Implicit theories of emotion: Affective and social outcomes across a major life transition. Journal of Personality and Social Psychology, 92, 731-744.

Thompson, L.L. (1991). Information exchange in negotiation. Journal of Experimental Social Psychology, 27, 161-179.

Wong, E.M., Haselhuhn, M.P., \& Kray, L.J. (2012). Improving the future by considering the past: The impact of upward counterfactual reflection and implicit beliefs on negotiation performance. Journal of Experimental Social Psychology, 48, 403-406. 
Table 1

Study 2: Correlations Between Variables

Variable

1. Implicit negotiation theories

2. Integrity perceptions (Time 1)

3. Integrity perceptions (Time 2)

4. Ethical attributions $(0=$ no ethical attribution; $1=$ ethical attribution $)$

Note: Significant correlations $(p<.05)$ are in boldface.
$2 \quad 3 \quad 4$

$--$

.10

$\begin{array}{lll}-.14 & .02 & --\end{array}$

$\begin{array}{lll}-.13 & -.05 & 32\end{array}$ 
Figure 1: Perceived deception as a function of implicit negotiation theories

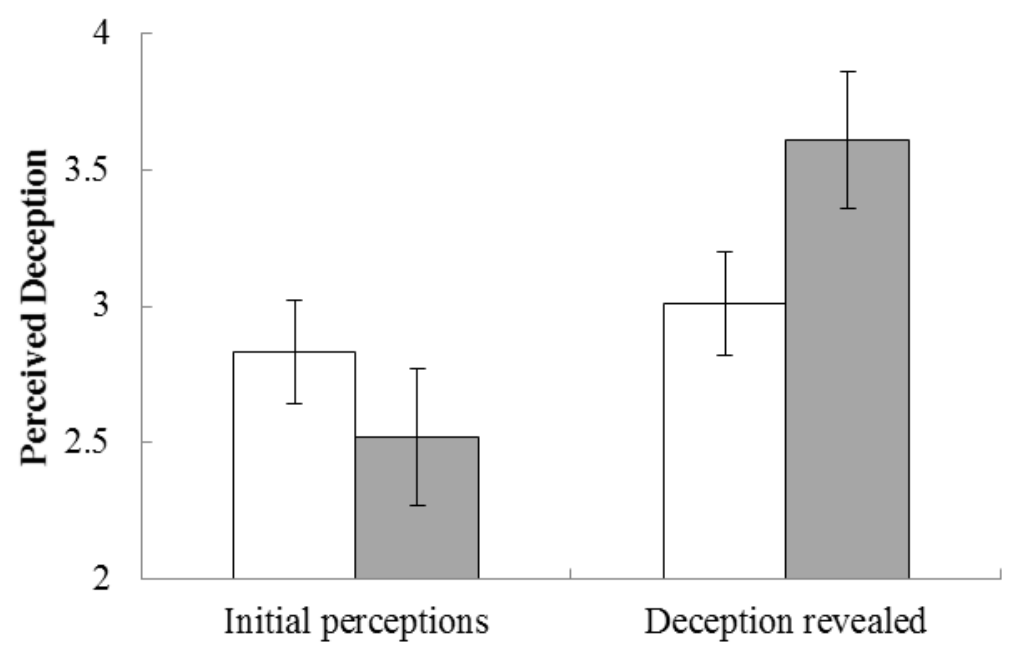

$\square$ Entity theorists $\square$ Incremental theorists 
Figure 2: Integrity-based trust following deception

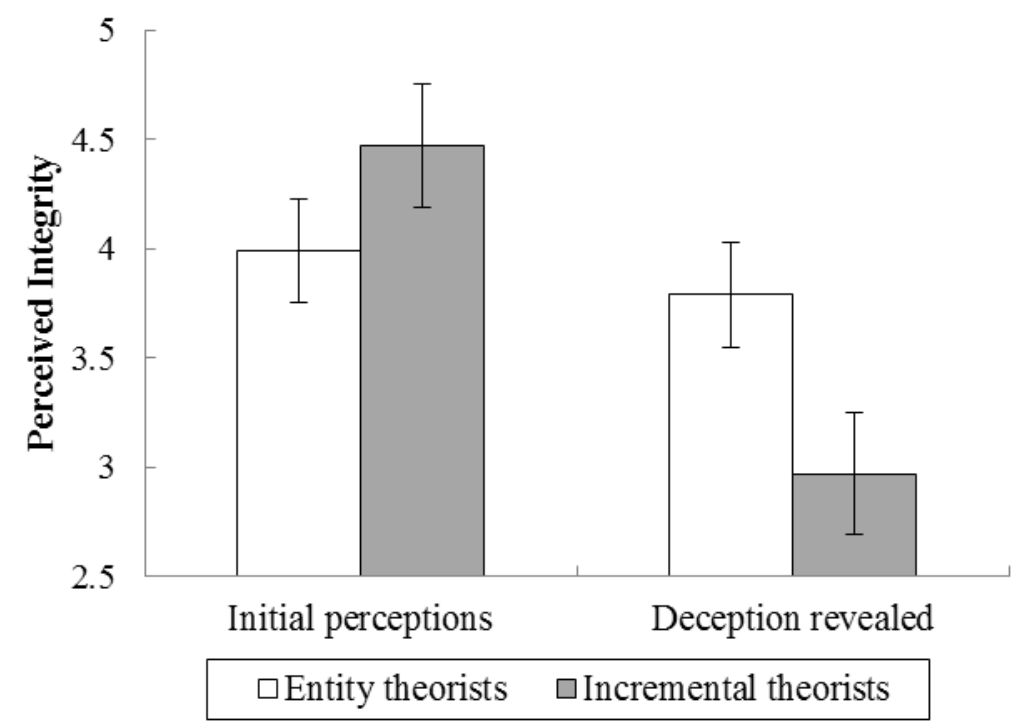

